ISSN: 1021-7444

\title{
MULTIPLICACIÓN IN VITRO VÍA ORGANOGÉNESIS EN CALABAZA ${ }^{1}$
}

\author{
Miguel Angel Sánchez-Hernández $z^{2,3}$, Cesar Sánchez-Hernández ${ }^{2}$, Clemente Villanueva-Verduzco ${ }^{4}$, \\ Isaías Gil-Vázquez ${ }^{4}$, María Concepción Jiménez-Rojas 4 , Irma Sánchez-Cabrera ${ }^{5}$
}

\section{RESUMEN}

Multiplicación in vitro vía organogénesis en calabaza. En la Universidad Autónoma Chapingo en México en el año 2004, se efectuó una investigación para establecer las condiciones in vitro para la inducción de organogénesis directa y caracterizar la capacidad de respuesta al cultivo in vitro de dos genotipos de calabaza (Cucurbita pepo L.): variedad 'Brujita' y 'Round Zucchini' (semilla sin testa) y establecer el proceso de aclimatización de las plántulas obtenidas vía organogénesis in vitro. Se empleó el medio de cultivo básico de Murashige y Skoog (1962) complementado con 1,0 mg/l de 6-Bencilaminopurina (BAP). Después de tres semanas de inducción en el medio de cultivo, los explantes de las dos variedades regeneraron brotes. Los brotes adventicios fueron subcultivados para su elongación y emisión de raíces en el medio de cultivo Murashige y Skoog sin la hormona BAP. La aclimatización de las plántulas obtenidas se realizó en charolas de plástico con Peat Moss ${ }^{\circledR}$ como sustrato y cubiertas con plástico transparente simulando un microinvernadero. En el incremento in vitro existieron diferencias en la tasa de multiplicación entre genotipos, 3,2 brotes por explante (yema) en la variedad 'Round Zucchini' y 2,7 brotes en la variedad 'Brujita', con subcultivos cada veintidós días. El proceso de aclimatización bajo invernadero logró una sobrevivencia de 90,10\% de plántulas en la variedad 'Brujita' y de $73,75 \%$ en la variedad 'Round Zucchini' en un periodo de veinte días.

\section{ABSTRACT}

In vitro multiplication via organogenesis in squash. This study was carried out at Univiersidad Autonoma of Chapingo, Mexico, in 2004, to develop appropriate protocols for the induction of direct organogenesis and to characterize in vitro regeneration capacity of two squash (Cucurbita pepo L.) genotypes: the 'Brujita' variety and the 'Round Zucchini' variety (coat-less seed), and to develop acclimation procedures for plantlets obtained in vitro. Murashige and Skoog (1962) culture media, supplemented with 1,0 mg/l of 6-benzylaminopurine (BAP), was used. After three weeks of induction in the culture media, explants of the two varieties regenerated sprouted. Adventitious shoots were sub-cultured to allow their rooting and elongation in Murashige and Skoog media without the BAP hormone. The acclimation of the plantlets was carried out in plastic trays containing Peat Moss ${ }^{\circledR}$ as substrate and covered with transparent plastic simulating a "micro-greenhouse". In vitro multiplication rate differed among genotypes; the coat-less seed 'Round Zucchini' variety had 3,2 plantlets per bud (explant) and the 'Brujita' variety had 2,7, counted every twenty two days. The acclimation process used yielded $90 \%$ survival the 'Brujita' variety plantlets, and $76 \%$ survival in the coat-less seed 'Round Zucchini' variety.

Key words: Cucurbitaceae, micro-propagation, hormones, acclimatization, varieties.

Palabras clave: Cucurbitaceae, micropropagación, hormonas, aclimatización, variedades.

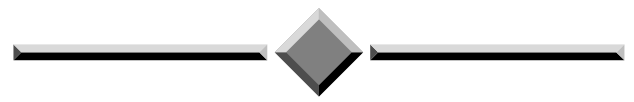

Recibido: 5 de octubre, 2007. Aceptado: 20 de marzo, 2009.

2 Egresado de la Maestría en Horticultura. Universidad Autónoma Chapingo. Km. 38,5 Carretera México-Texcoco. Chapingo, Estado de México. C. P. 56230. Correo electrónico: mangelsan@ hotmail.com, cesarsh79@ hotmail.com

3 Universidad del Papaloapan. Av. Ferrocarril Hidalgo s/n. Ciudad Universitaria Loma Bonita, Oaxaca, México. C. P. 68400 Tel. y Fax: 01(281) 872-2239. Correo electrónico: msanchez@lomabonita.unpa.edu.mx

4 Departamento de Fitotecnia. Universidad Autónoma Chapingo, Km. 38,5 Carretera México-Texcoco. C. P. 56230. Chapingo, Estado de México. Tel. y Fax: 01 (595) 952-1500. Correo electrónico: clemente@taurus1.chapingo.mx; isaiasgilvazquez@yahoo.com.mx; marconjiro@hotmail.com

5 Instituto de Recursos Genéticos y Productividad. Colegio de Postgraduados, Km. 36,5 Carretera México-Texcoco. C. P. 56230. Montecillo, Estado de México. Tel. 01 (595) 952-0200. Correo electrónico: isc1859@hotmail.com 


\section{INTRODUCCIÓN}

En México el cultivo de la calabaza (Cucurbita spp.) es importante, consumiéndose como hortaliza o fruto maduro debido a que su pulpa es rica en carbohidratos, provitamina A y fibra soluble, las semillas son ricas en proteína (32-40\%) y aceite vegetal (40\%) (Sánchez et al. 2006). De ahí que los programas modernos de mejoramiento genético de calabazas se enfoquen a incrementar el rendimiento de frutos por planta, mejorar el color, grosor y sabor de la pulpa, número de semillas por fruto, contenido de aceite en la semilla; además de generar resistencia en la planta contra plagas y enfermedades (Villanueva et al. 1998, Urbanek et al. 2004).

En la República Mexicana no existen variedades arbustivas de calabaza con semilla sin testa, mismas que podrían usarse como: 1) semillas tostadas de calabaza como botana, 2) la industria extraería aceite dado que en evaluaciones bromatológicas se encontró que la semilla tiene un $38 \%$ de aceite y el país importa el $80 \%$ del aceite que consume, además de que se carece de variedades comerciales con frutos color anaranjado (tipo brujita) los cuáles se importan de Estados Unidos de Norteamérica el 1 y 2 de noviembre.

Las semillas sin testa aparecieron como una mutación en un lugar desconocido en Europa Central hace casi 100 años, éstas substituyeron a las semillas de calabaza normales en Austria desde hace 50 años. Styria, una provincia de la región sudeste de Austria, es la principal zona productora de calabaza productora de semilla sin testa para la extracción de aceite. En 1998 la Comunidad Europea reconoció oficialmente el aceite de semilla de calabaza "Styrian Pumpkin-Seed Oild g.g.A." con estampilla de origen (Winkler 2000).

Martínez et al. (1996) reportaron el contenido de aceite de dos accesiones de calabaza de semilla sin testa con valores de 35,0 y $37,0 \%$. Por su parte, Abak et al. (1997) citados por Winkler (2000), evaluaron cuatro líneas de calabaza de semilla sin testa en Turquía y reportaron $39-40 \%$ de aceite.

Genéticamente el intervalo en colores de la cáscara del fruto de calabaza va de verde hasta amarillo y anaranjado, así como intensidades de color desde casi negro hasta casi blanco. Generalmente, bajo la influencia del alelo normal $\mathrm{B}^{+}$, los ovarios de C. pepo son de color verde antes de antesis, pero después de antesis cambian a una gran variedad de colores y patrones, dependiendo de la constitución genética de la planta.
Se han identificado varios genes que determinan el color externo del fruto, uno de éstos el gene $\mathrm{Y}$ determina que la cáscara del ovario pierda su pigmentación verde algún tiempo después de antesis, cambiando su coloración a amarillo o anaranjado (Paris 2000).

El cultivo de tejidos vegetales es una herramienta que permite la regeneración de plantas en corto tiempo, lo que ayuda a mejorar y mantener la diversidad en calabazas, asegurando la disponibilidad de materiales de siembra para los agricultores y los programas de mejora genética de la especie. En la literatura científica se reportan técnicas de regeneración in vitro en $\mathrm{Cu}$ curbita a partir de explantes de cotiledón (Gambley y Dodd 1991, Kathiravan et al. 2006), hipocótilo (Shakti et al. 2007), hipocótilo, cotiledón y raíz (Hiroshi et al. 2003), hoja (Mishra y Bhatnagar 1995), hoja y cotiledón (Stripp et al. 2001), antera (Metwally et al. 1998, Kumar et al. 2003), y óvulos (Metwally et al. 1998). Sin embargo, no se reporta inducción de brotes a partir del ápice de semillas germinadas in vitro. En este tenor, se seleccionó el regulador de crecimiento 6-Bencilaminopurina (BAP) por la baja frecuencia de plantas tetraploides obtenidas por organogénesis.

Pink y Walkey (1984) realizaron una rápida multiplicación de clones de $C$. pepo cultivar 'Cinderella' empleando meristemos de 0,5-1,0 $\mathrm{mm}$ de plántulas germinadas in vitro, la inducción de brotes fue en el medio de cultivo de Murashige y Skoog (1962) (MS), se evaluaron 16 tratamientos resultado de la combinación de cuatro concentraciones de kinetina $(0,2,56$, $12,8$ y $25,6 \mathrm{mg} / \mathrm{l})$ y cuatro de AIA $(0,8,16$ y $32 \mathrm{mg} / \mathrm{l})$; en todos los tratamientos se observó poca formación de callo y no hubo proliferación de brotes. En un segundo experimento se ensayó el efecto de tres concentraciones de BA (1, 2,5 y $5 \mathrm{mg} / \mathrm{l})$ combinado con 1 mg/l de AIA, AIB y ANA. La máxima proliferación de brotes se obtuvo con $1 \mathrm{mg} / \mathrm{l}$ de BA sin auxinas.

Lee y Thomas (1985) sembraron como fuente de explante yemas axilares de calabaza búfalo ( $C$. foetidissima $\mathrm{HBK}$ ) en medio de cultivo MS suplementado con $1,5 \mathrm{mg} / \mathrm{l}$ de BAP y $0,1 \mathrm{mg} / \mathrm{l}$ de ácido naftalenacético. Lograron obtener plántulas vigorosas que posteriormente se transplantaron en sustrato estéril, y en condiciones de invernadero prosperaron de manera exitosa.

Metwally et al. (1998) utilizaron anteras y óvulos de calabaza como explantes, con el objetivo de obtener plantas dobles haploides y con ello líneas puras, deseables para generar híbridos, sintéticos y nuevos cultivares. Evaluaron diferentes pretratamientos con 
temperatura fría a $4{ }^{\circ} \mathrm{C}$ (por $0,2,4$ y 8 días) sobre la embriogénesis y utilizando medio MS suplementado con $30 \mathrm{~g} / \mathrm{l}$ de sucrosa, $8 \mathrm{~g} / \mathrm{l}$ de agar y cuatro concentraciones de la auxina 2,4-D $(0,1 ; 1,0 ; 5,0$ y $10 \mathrm{mg} / \mathrm{l})$, encontraron que el tratamiento a $4{ }^{\circ} \mathrm{C}$ (por dos, cuatro u ocho días) suprime la embriogénesis. El número de plántulas obtenidas aumentó a medida que se incrementó la concentración de 2,4-D en el medio de cultivo de 0,1 a $5 \mathrm{mg} / \mathrm{l}$.

En cultivo de tejidos se aprovecha el fenómeno de totipotencia celular, que es la capacidad de las células somáticas de regenerar el fenotipo de la planta de la cual se derivan. Puede manifestarse por dos rutas alternativas: 1) organogénesis; es decir, la diferenciación de meristemos caulinares y/o radiculares y, 2) embriogénesis concebida como la formación de embriones somáticos siguiendo las fases del embrión cigótico (Segura 1993). De acuerdo con Pierik (1990) ocurren cuatro etapas en el proceso: 1) desdiferenciación de células diferenciadas, 2) división celular, 3) iniciación de órganos, y 4) desarrollo de órganos.

Una planta proveniente de cultivo in vitro, difiere en muchos aspectos de las que se originan in vivo, presentan una cutícula poco desarrollada, por la alta humedad relativa (90-100\%) que se tiene in vitro. Las hojas de estas plantas además de ser finas y blandas, fotosintéticamente son poco activas; y por consiguiente, cuando se transfieren al suelo pueden verse seriamente afectadas por las condiciones que se encuentran in vivo. Además, la conducción de agua entre vástagos y raíces puede verse reducida por una pobre conducción vascular. Es importante tener en cuenta que las plantas in vitro han sido desarrolladas como heterótrofas, pero deben comportarse como autótrofas in vivo, ya que los azúcares deben ser producidos por medio de la fotosíntesis (Pierik 1990).

Las raíces que se han originado in vitro son vulnerables y no funcionan de forma adecuada in vivo, ya que carecen de pelos radicales o tienen pocos, por lo que mueren rápidamente debiendo ser sustituidas por nuevas raíces subterráneas. La aparición y desarrollo de pelos radicales de plántulas obtenidas in vitro puede estimularse al colocar las raíces en un medio líquido. Un desarrollo pobre del sistema radical hace que el crecimiento in vivo se haga muy difícil, especialmente cuando hay una elevada transpiración (Ammirato et al. 1990, Vasil y Thorpe 1994).

Las plantas procedentes de cultivo de tejidos tienen las células en empalizada más pequeñas y en menor cantidad que las plantas in vivo. Los estomas de las plantas in vitro pueden no ser suficientemente operativos; y al permanecer abiertos, cuando la planta ha pasado al suelo, puede ser el origen de un importante estrés hídrico, durante las primeras horas de aclimatización. En este punto es importante indicar que la aclimatización es un proceso de adaptación de la planta regulado por el hombre, mientras que la aclimatación es un proceso de adaptación al ambiente regulado por la naturaleza (Brainerd y Fuchigami 1981).

A nivel comercial el proceso de aclimatización es necesario debido a que el material producido in vitro no está capacitado para tolerar un cambio a condiciones in vivo. Read y Fellman (1985), propusieron diseñar cámaras de crecimiento con altas humedades relativas dentro del invernadero, sugiriendo para ello que dichas cámaras cuenten con un sistema de niebla especial, que emita un tamaño de partícula de agua que permita su adecuada dispersión en el aire; un sistema de circulación de aire; calefacción opcional; un sistema de microaspersión y luz para poder controlar intensidades lumínicas.

Diferentes autores recomiendan que para transplantar las plántulas obtenidas in vitro del medio de cultivo al suelo u otro sustrato estéril es deseable: 1) evitar infecciones por hongos y bacterias; por lo que, el agar (con azúcar) debe eliminarse completamente y utilizar suelo esterilizado de preferencia con vapor; 2) para evitar daños a las raíces, es recomendable plantar en suelo finamente tamizado o algún sustrato como Peat Moss ${ }^{\circledR}$; 3) regar las plántulas recién transplantadas con una solución de fungicida; 4) si se tienen las posibilidades, se deben instalar cortinas de humedad con sistemas de niebla automáticos (Ammirato et al. 1990, Pierik 1990, Vasil y Thorpe 1994). Cabe señalar que en artículos publicados sobre regeneración in vitro de Cucurbitaceas se pone muy poco énfasis en el proceso de aclimatización de las plántulas obtenidas vía embriogénesis y/o organogénesis, sólo se indican los porcentajes de sobrevivencia de plántulas al ser transferidas a suelo, por lo que este trabajo tuvo como objetivo desarrollar y describir una metodología práctica y eficiente del proceso de aclimatización de plántulas de calabaza obtenidas in vitro al ser transferidas a suelo.

Sarowar et al. (2003), micropropagaron in vitro un híbrido de calabaza, derivado de $C$. moschata x $C$. maxima, importante en Korea y Japón, ya que se utiliza como porta injerto por conferir vigor y resistencia a enfermedades en variedades comerciales de sandía y 
calabaza. Utilizaron como explantes secciones de 3-4 cm de cotiledón e hipocótilo, y diferentes concentraciones de BA y ANA para inducir brotes. El 55\% de plántulas sobrevivió después de transferirse al suelo y desarrollaron frutos después de dos meses.

Urbanek et al. (2004) evaluaron la regeneración de Cucurbita pepo L. Subs. pepo var. styriaca Grez. vía embriogénesis somática, reportan que durante la aclimatización el $30 \%$ de plántulas murió por incidencia de enfermedades fungosas. El 5\% de plántulas tuvieron crecimiento reducido, y un $65 \%$ se desarrolló normalmente comparado con plantas testigo derivadas de semilla. Después de aclimatización las plántulas se transplantaron en campo, donde crecieron normalmente y desarrollaron frutos maduros de $1,5 \mathrm{~kg}$ de peso con un promedio de 378 semillas.

Cuando una nueva variedad ha sido creada y se piensa liberarla, se parte de una limitada cantidad de semilla que debe incrementarse para satisfacer las necesidades del mercado. Sembrar esta semilla, la cual es escasa se corre el riesgo de que se pierda, además de que se requerirán varios ciclos de cultivo para obtener suficiente cantidad de semilla; una opción para incrementar el número de plantas y semillas en poco tiempo es el uso de la técnica de micropropagación in vitro, donde a partir de un ápice de planta seleccionada, es posible producir una infinidad de nuevas plantas, las cuales conservarán las características genéticas de la planta original.

En la actualidad existen diferentes protocolos de regeneración in vitro para diferentes especies vegetales utilizando como explantes: brotes adventicios, cultivo de protoplastos, embriogénesis somática entre otros. No obstante, la eficiencia en micropropagación por sí sola, no asegura que las plantas generadas sean normales y fructifiquen cuando se llevan a campo o invernadero, ya que a veces solo se obtienen estructuras rudimentarias. Cuando se regeneran plantas vía embriogénesis somática puede generarse variación somaclonal aún dentro de un mismo clon (Larkin y Scowcroft 1981), lo cual puede confundirse con el efecto de la variación ambiental dentro del clon. En contraste, clones derivados del cultivo de ápices de meristemos son más uniformes genéticamente $(\mathrm{Mu}-$ rashige 1974).

Por lo antes expuesto la presente investigación tuvo como objetivos: incrementar in vitro dos genotipos avanzados de calabaza (Cucurbita pepo L.) tipo 'Round Zucchini' productora de semilla sin testa y uno tipo 'Brujita' (frutos color anaranjado) y, lograr la máxima sobrevivencia de plántulas durante el proceso de aclimatización en invernadero.

\section{MATERIALES Y MÉTODOS}

El ensayo se condujo en el Laboratorio de Biotecnología sección cultivo de tejidos del Departamento de Preparatoria Agrícola de la Universidad Autónoma Chapingo en México durante los meses de abril a agosto de 2004; la Universidad se localiza geográficamente a los $19^{\circ} 32^{\prime} \mathrm{LN}$ y $98^{\circ} 51^{\prime} \mathrm{LW}$ a una altura de $2.240 \mathrm{msnm}$ (García 1988). Se usaron dos variedades experimentales del programa de mejoramiento genético de calabazas de la Universidad Autónoma Chapingo, 'Round Zucchini' de semilla sin testa, la cual se obtuvo mediante selección y autofecundación de segregantes de la cruza Cucurbita pepo L. de semilla sin testa (obtenida del Banco de Germoplasma del Campo Agrícola Experimental INIFAP ubicado en Celaya, Guanajuato, México) por 'Round Zucchini' (C. pepo L.). Además, de la variedad arbustiva 'Brujita' (C. pepo L.), llamada así por el color naranja de los frutos. Este tipo de frutos de calabaza tienen una gran demanda en día de muertos en México ( 1 y 2 de noviembre), misma que se satisface con importaciones de los Estados Unidos de Norteamérica.

\section{Desinfestación de la semilla}

La semilla de la variedad 'Round Zucchini' productora de semilla sin testa mide $1,53 \mathrm{~cm}$ de largo y $0,77 \mathrm{~cm}$ de ancho, color verde marrón y 100 semillas pesan $15 \mathrm{~g}$. Por su parte la semilla de la variedad 'Brujita' presenta un largo y ancho de 1,57 y $0,89 \mathrm{~cm}$, respectivamente, color crema en toda su superficie, incluyendo el margen de la misma, el peso de $100 \mathrm{se}-$ millas es de $13 \mathrm{~g}$. Se usaron cinco semillas de cada genotipo y se envolvieron en un trozo de tela (manta de cielo), se amarraron y después se llevaron a lavar con agua limpia y jabón (detergente) en un vaso de precipitado durante diez minutos. Luego se sumergieron en una solución con 1,0 g/l de los fungicidas Benlate ${ }^{\circledR}$, Captan ${ }^{\circledR}$ y Tecto $60^{\circledast}$ por 25 minutos. Transcurrido este tiempo se enjuagaron y el material se llevó a una campana de flujo laminar donde las semillas se colocaron en una solución de hipoclorito de sodio al 25\% (v/v) adicionado con 20 gotas de Mycrodin ${ }^{\circledR}$ y dos gotas de Tween $20^{\circledR}$ durante 20 minutos. 
Después, las semillas se pasaron a una solución de peróxido de hidrógeno al 3\% durante 20 minutos, se enjuagaron tres veces con agua destilada estéril y se procedió a sembrar tres semillas por frasco de vidrio de $250 \mathrm{ml}$ que contenían $40 \mathrm{ml}$ de medio de cultivo Murashige y Skoog (1962, MS) (Figura 1A), posteriormente se colocó una banda de cinta Agapack ${ }^{\circledR}$ alrededor del cuello del frasco, para cubrir el vacío entre el frasco y su tapa con la finalidad de evitar contaminación del material sembrado. En la variedad 'Brujita' se eliminó la cáscara de las semillas antes de sembrarlas en el medio MS. Luego, los frascos se llevaron a un cuarto de incubación a una temperatura promedio de $26 \pm 2{ }^{\circ} \mathrm{C}$, con un fotoperiodo de 16 horas luz (lámparas de luz blanca fría fluorescente, con intensidad lumínica de $50 \mu \mathrm{mol} / \mathrm{m}^{2} / \mathrm{s}$ ) y ocho horas de oscuridad.

\section{Fase de multiplicación}

Una vez que la semilla germinó y expuso la yema, se procedió a eliminar las hojas cotiledonares y se cortó la yema apical con una longitud de 2,0 cm la cual se transfirió a medio de cultivo MS adicionado con 1,0 mg/l de 6-Bencilaminopurina (BAP) para inducir la formación de brotes (Figura 1B, Figura 1C). Esta

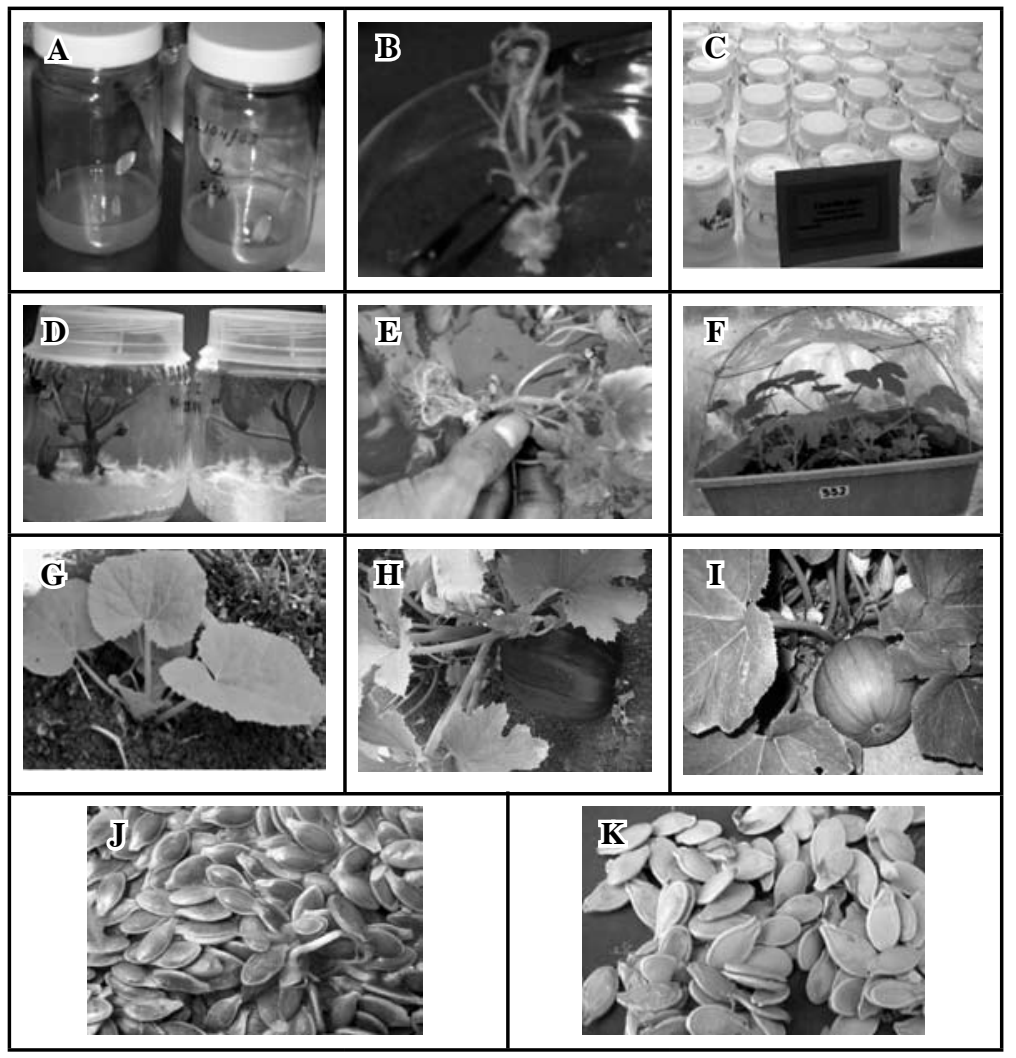

Figura 1. Esquema metodológico de las fases de laboratorio e invernadero para el incremento de semilla básica de calabaza en Chapingo, México. 2004. A) Siembra de las semillas de calabaza en el medio de cultivo MS + 1,0 mg/l de BAP; B) Trasvase de brotes; C) Crecimiento de brotes; D) Enraizamiento de brotes en el medio de cultivo MS sin BAP; E) Eliminación de agar de las raíces; F) Aclimatización de las plantas obtenidas in vitro en microinvernadero; G) Transplante de las plantas aclimatizadas en tezontle rojo en invernadero; H) Cosecha de frutos de la var. 'Round Zucchini' de semilla sin testa; I) Cosecha de frutos de la var. 'Brujita'; J) Semilla de la variedad 'Round Zucchini'; K) Semilla de la var. 'Brujita'. 
actividad se realizó cada cuatro semanas en promedio, el cual corresponde al tiempo en que las plantas han agotado las reservas del medio de cultivo.

\section{Fase de enraizamiento de brotes}

De cada brote inicial se obtuvieron 27 y 36 brotes en la variedad 'Brujita' y 'Round Zucchini', respectivamente, en cinco ciclos de multiplicación se generaron 135 y 180 brotes al final de la fase de multiplicación in vitro de las variedades indicadas. Los brotes medían en promedio de 2 a $3 \mathrm{~cm}$ de longitud, y se transfirieron al medio de cultivo MS sin la hormona BAP, para promover el enraizamiento y elongación de los brotes y obtener las plantas completas in vitro (Figura 1D).

\section{Preaclimatización}

Las plántulas entre 4 y $5 \mathrm{~cm}$ obtenidas in vitro una vez que desarrollaron raíces y se habían alongado (Figura 1D), se trasladaron a un invernadero del Campo Agrícola Experimental de la Universidad Autónoma Chapingo, procurando realizar esta actividad por la mañana para no dañarlas por el calor. Ya dentro del invernadero, la preaclimatización consistió en eliminar de los frascos la cinta de Agapack $^{\circledR}$ y destaparlos, dejándose bajo malla sombra durante 48 horas, con la finalidad de que las plantas comenzaran a adaptarse a condiciones diferentes a las existentes en el laboratorio donde estaban a temperatura promedio de $26 \pm 2{ }^{\circ} \mathrm{C}$ y fotoperiodo de 16 horas luz (lámparas de luz blanca fría fluorescente, con intensidad lumínica de $50 \mu \mathrm{mol} /$ $\mathrm{m}^{2} / \mathrm{s}$ ) y ocho horas de oscuridad.

\section{Transferencia a sustrato}

Antes de transplantar, se eliminó completamente el medio de cultivo (agar) de las raíces (Figura 1E), para ello se colocaron las plántulas en un recipiente con agua limpia de pozo profundo y el medio se eliminó de las raíces manualmente sin dañar a las plántulas. Con la finalidad de evitar contaminación por enfermedades fungosas, las plántulas se sumergieron durante cinco minutos en un recipiente que contenía una solución preparada con fungicida Captan $50 \mathrm{PH}^{\circledR}$ a razón de 1,0 $\mathrm{g} / \mathrm{l}$ de agua.

Para el transplante se utilizó como sustrato Peat Moss $^{\circledR}$, el cual se esterilizó en autoclave durante una hora a $15 \mathrm{lb} / \mathrm{pulg}^{2}$ a $121{ }^{\circ} \mathrm{C}$. Como contenedores se utilizaron charolas de plástico de 45 x 35 x $11 \mathrm{~cm}$; que se desinfectaron con una solución de hipoclorito de sodio al $10 \%$ durante un día; a las charolas se les colocó un arco de alambre galvanizado en cada extremo angosto, anclados en las esquinas internas de la charola, los cuáles se unieron con dos alambres (uno a cada lado) a $3 / 4$ de la altura de los arcos para darle forma. El plástico de la parte superior del microinvernadero quedó de manera cóncava para que el agua al condensarse en esta parte precipitara dentro de la charola y se reciclara; con lo que se mantuvo una alta humedad relativa (Figura 1F).

A cada charola se le depositó un promedio de 800 $\mathrm{g}$ de Peat Moss ${ }^{\circledR}$ esterilizado, el cual se humedeció a capacidad de campo con agua limpia de pozo profundo para después trasplantar 20 plántulas por charola, tratando de que todas quedaran a la misma distancia.

Una vez realizado el trasplante en las charolas se procedió a dar un riego ligero con solución nutritiva empleando la fórmula de Steiner (1984) al 100\%, después la charola se introdujo al interior de una bolsa grande de plástico transparente y se le cerró la boca simulando un microinvernadero (Figura 1F). Las charolas cubiertas con el plástico transparente se colocaron a una altura de $1,20 \mathrm{~m}$ del suelo sobre tres hilos de alambre galvanizado en un invernadero tipo túnel con ventilación cenital, en el invernadero se tuvieron temperaturas promedio de $30{ }^{\circ} \mathrm{C}$, humedad relativa de $80 \%$ y una intensidad luminosa de 3.500 luxes.

A los ocho días, conforme las plantas se fueron adaptando al plástico, se le hicieron dos perforaciones de $2,5 \mathrm{~cm}$ de diámetro en los extremos, y cada tres días se hacían otros dos hasta destapar completamente la charola.

\section{Análisis estadístico}

A) Multiplicación in vitro. Los datos de multiplicación in vitro se analizaron como un experimento factorial 2x5, lo que correspondió al ensayo de dos variedades de calabaza, cinco fechas de subcultivo y cinco repeticiones. Las repeticiones fueron cada una de las semillas que se sembraron originalmente en el medio básico de cultivo MS. Los brotes generados por cada yema (repetición) se volvían a establecer en el medio de cultivo $\mathrm{MS}+1,0 \mathrm{mg} / \mathrm{l}$ de BAP, de esta manera se siguió la tasa de multiplicación de cada variedad 
por fecha de subcultivo en un diseño experimental completamente al azar.

B) Aclimatización. Los datos provenientes de aclimatización de plantas se analizaron tomando como tratamientos a las variedades y como repeticiones a las charolas donde se transplantaron 20 plántulas provenientes de multiplicación in vitro.

Tanto para multiplicación in vitro como en aclimatización los datos se sometieron a un análisis de varianza con el procedimiento GLM de SAS (SAS Institute 1989) y se realizaron pruebas de comparación de medias entre tratamientos por Tukey $(\mathrm{P} \leq 0,05)$.

\section{RESULTADOS Y DISCUSIÓN}

\section{Multiplicación in vitro de genotipos}

La diferenciación de brotes se logró tanto en la variedad 'Brujita' como en 'Round Zucchini', con el medio de cultivo utilizado. Existieron diferencias estadísticas altamente significativas al $1 \%$ de probabilidad para número de brotes entre las variedades $(\mathrm{V})$ y fechas de subcultivo (F), excepto para la interacción variedades por fecha de subcultivo $(\mathrm{V} * \mathrm{~F})$. El coeficiente de variación fue de $8,64 \%$ lo que indica una consistencia de la información con el modelo estadístico utilizado (Cuadro 1). La diferenciación de brotes se dio debido a que las condiciones experimentales permitieron a los tejidos manifestar su potencialidad morfogénica. Lo anterior es apoyado por el hecho de que los explantes de ambas variedades mantuvieron un alto nivel de respuesta a la inducción de brotes.

El regulador de crecimiento 6-Bencilaminopurina (BAP) promovió la inducción y crecimiento de brotes de calabaza. Al respecto, Quintanilla (2007) sostuvo que la 6-Bencilaminopurina es una citocinina sintética que se utiliza en concentraciones de $0,1 \mathrm{a} 1 \mathrm{mg} / \mathrm{l}$ para promover la división celular y la inducción de yemas adventicias en callos y órganos y en la proliferación de tallos axilares debido a que incide en la ruptura de la dominancia apical. Lo anterior coincide con lo reportado por Hiroshi et al. (2003) al evaluar la regeneración vía organogénesis de las variedades Juktoja y Miyako de calabaza (Cucurbita maxima) empleando BAP en diferentes concentraciones $(1,2,5$ y $10 \mathrm{mg} / \mathrm{l})$ usando como explantes secciones de cotiledón; de 213 plantas regeneradas únicamente se obtuvo una planta
Cuadro 1. Análisis de varianza para número de brotes por fecha de subcultivo in vitro de dos variedades de calabaza (Cucurbita pepo L.). Chapingo, México. 2004.

\begin{tabular}{|c|c|c|c|c|c|}
\hline $\begin{array}{l}\text { Fuente de } \\
\text { variación }\end{array}$ & & S.C. & C.M. & FC & $\operatorname{Pr}>\mathbf{F}$ \\
\hline $\begin{array}{l}\text { Variedades } \\
\text { (V) }\end{array}$ & & 6,6248 & 6,6248 & 95,87 & $0,0001 * *$ \\
\hline Fechas $(F)$ & & 4,1040 & 1,0260 & 14,85 & $0,0001 * *$ \\
\hline $\begin{array}{l}\text { Interacción } \\
\mathrm{VxF}\end{array}$ & & 0,4472 & 0,1118 & 1,62 & $0,1886 \mathrm{~ns}$ \\
\hline $\mathrm{CV}(\%)$ & 8,64 & & & & \\
\hline $\mathrm{R}^{2}$ & 0,80 & & & & \\
\hline
\end{tabular}

C.V. $=$ Coeficiente de variación $(\%) ; \mathrm{R}^{2}=$ Coeficiente de determinación; S.C. $=$ Suma de cuadrados; C.M.= Cuadrados medios; $\mathrm{FC}=\mathrm{F}$ calculada de Snedecor; *= Significancia de los tratamientos al 0,05 de probabilidad; $* *=$ Significancia de los tratamientos al 0,01 de probabilidad; ns= no significativo.

tetraploide, indicando que esta hormona es efectiva para la regeneración de plantas diploides.

Pink y Walkey (1984) realizaron una rápida multiplicación de clones de Cucurbita pepo cultivar 'Cinderella' emplearon meristemos de 0,5-1,0 mm de plántulas germinadas in vitro, la inducción de brotes fue en el medio de cultivo MS, se evaluaron 16 tratamientos resultado de la combinación de cuatro concentraciones de kinetina $(0 ; 2,56 ; 12,8$ y $25,6 \mathrm{mg} / \mathrm{l})$ y cuatro de AIA $(0$, $8,16$ y $32 \mathrm{mg} / \mathrm{l})$; en todos los tratamientos se observó poca formación de callo y no hubo proliferación de brotes. En un segundo experimento se ensayó el efecto de tres concentraciones de BA $(1 ; 2,5$ y $5 \mathrm{mg} / \mathrm{l})$ combinado con $1 \mathrm{mg} / \mathrm{l}$ de AIA, AIB y ANA. La máxima proliferación de brotes se obtuvo con $1 \mathrm{mg} / \mathrm{l}$ de BA sin auxinas.

En variedades se encontró que 'Round Zucchini' generó 3,2 brotes por explante con yema apical, mientras que 'Brujita' presentó 2,7 brotes en el medio de cultivo básico MS adicionado con 1,0 mg/l de 6Bencilaminopurina (Cuadro 2). En los dos genotipos se utilizó el mismo tipo de explante (ápice de 2,0 cm de longitud), por lo tanto, las diferencias en capacidad organogénica se atribuyen a variación genética en la concentración endógena de hormonas, lo que es consistente con lo reportado por López et al. (1992) 
Cuadro 2. Prueba de comparación de medias por Tukey $(\mathrm{P} \leq 0,05)$ para número de brotes por variedad en medio de cultivo MS + 1,0 mg/l de BAP. Chapingo, México. 2004.

\begin{tabular}{lc}
\hline \multicolumn{1}{c}{ Variedad } & Media \\
\hline 'Round Zucchini' & $3,2 \mathrm{a}$ \\
'Brujita' & $2,7 \mathrm{~b}$ \\
DMS* & 0,1503 \\
\hline
\end{tabular}

* DMS=Diferencia mínima significativa de Tukey al 0,05 de probabilidad.

e Iracheta (1995), quienes estudiaron la inducción de brotes en jitomate (Lycopersicon esculentum Mill.), otra razón es que la cantidad de receptores moleculares hormonales en la membrana plasmática de los tejidos pudo ser diferente (Sheridan 1988).

Metwally et al. (1998) declararon que la regeneración de plantas en calabaza (C. pepo L.) depende del tipo y concentración de reguladores de crecimiento usados para la inducción.

Hiroshi et al. (2003) reportaron que el 82 y $92 \%$ de los explantes de cotiledón de la variedad Juktoja y Miyako de C. maxima, respectivamente, regeneraron brotes después de cuatro semanas en medio de cultivo MS con $1 \mathrm{mg} / \mathrm{l}$ de BAP.

En relación con el efecto del genotipo Santalla et al. (1998) utilizaron diez líneas mejoradas de Phaseolus vulgaris y 17 líneas de $P$. coccineus para evaluar la capacidad organogénica, usando cotiledones como explantes; reportaron que la respuesta al cultivo in vitro y la habilidad de regeneración varía significativamente entre especies y genotipos, y que $P$. coccineus produce más brotes por explante y mejor enraizados que $P$. vulgaris, evidenciando que el genotipo es importante en la respuesta al cultivo de tejidos in vitro.

En subcultivos, la primera y segunda fecha generaron el mayor número de brotes por explante, encontrándose una tendencia a disminuir el número de brotes generados conforme aumentó su número (Cuadro 3). En los últimos dos subcultivos se tuvo una menor cantidad de brotes emitidos por yema; 2,73 y 2,70 ; respectivamente. Lo anterior, se relaciona con una disminución en la capacidad regenerativa del tejido, al ser sometido a varios ciclos de subcultivo, esta disminución en la capacidad regenerativa del tejido probablemente se debió a una variación en la concentración endógena de
Cuadro 3. Comparación múltiple de medias por Tukey $(\mathrm{P} \leq 0,05)$ para número de brotes por fecha de subcultivo en medio de cultivo MS $+1,0 \mathrm{mg} / \mathrm{l}$ de BAP. Chapingo, México. 2004.

\begin{tabular}{ll}
\hline \multicolumn{1}{c}{ Fecha de subcultivo } & Media \\
\hline $15 / 03 / 04$ & $3,43 \mathrm{a}$ \\
$06 / 04 / 04$ & $3,25 \mathrm{~b}$ \\
$26 / 04 / 04$ & $3,09 \mathrm{~b}$ \\
$17 / 05 / 04$ & $2,73 \mathrm{c}$ \\
$08 / 06 / 04$ & $2,70 \mathrm{c}$ \\
DMS* & 0,3358 \\
\hline
\end{tabular}

* DMS=Diferencia mínima significativa de Tukey al 0,05 de probabilidad.

hormonas de los explantes conforme se incrementó el número de subcultivos, ya que pudo sintetizarse una mayor cantidad de auxinas lo que ocasionó menor proliferación de brotes. En este tenor Santalla et al. (1998) reportaron que las citocininas inducen organogénesis en cultivo de tejidos en presencia de auxina y en los casos en que no es necesario el complemento exógeno de auxinas para la división celular, se asume que el sistema las está sintetizando. Ananthakrishnan et al. (2003) en $C$. pepo bajo cultivo in vitro adicionado con benciladenina ( $1 \mathrm{mg} / \mathrm{l})$ encontraron que la máxima producción de brotes se tuvo durante el tercer ciclo de subcultivo y su producción disminuyó después del quinto subcultivo. Al respecto Litz y Jarret (1991) indicaron que el potencial organogénico de un explante es inversamente proporcional a su edad fisiológica. También los tejidos embrionarios y jóvenes generalmente tienen un alto grado de competencia morfogénica, conforme la planta envejece, la capacidad regenerativa tiende a disminuir (Conger 1981, Pierik 1990).

El número de brotes generados en la variedad 'Round Zucchini' de semilla sin testa fue de 3,8; 3,5; 3,$1 ; 3,0$ y 2,5 plantas por explante durante el primero, segundo, tercero, cuarto y quinto subcultivo, respectivamente, teniendo como promedio de multiplicación 3,2 brotes por explante por periodos de $22 \pm 2$ días. Por su parte la variedad 'Brujita' promedió una tasa de multiplicación de 3,$2 ; 2,6 ; 3,1 ; 2,5$ y 2,3 brotes por explante en medio básico de cultivo MS + 1,0 mg/l de 6-Bencilaminopurina (Figura 2). Con esa información se puede proyectar la cantidad de plantas a obtener en 


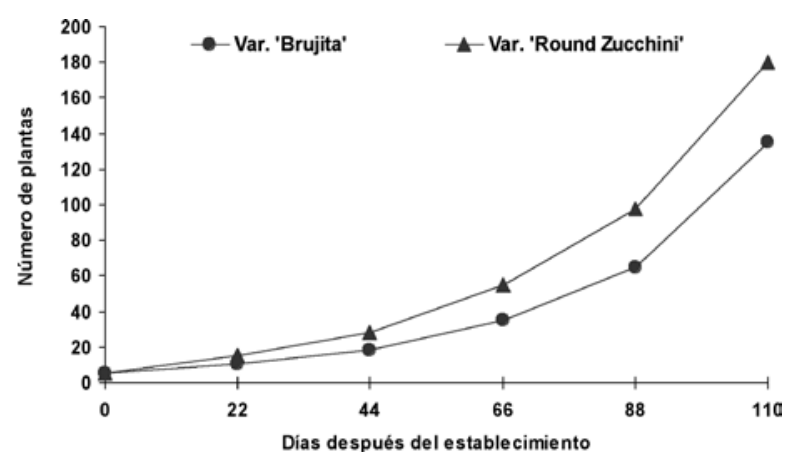

Figura 2. Tasa de multiplicación de calabaza (Cucurbita pepo L.) in vitro. Chapingo, México. 2004.

un determinado tiempo.

Los resultados presentados difieren de los encontrados por Bautista (2004), quien al realizar la micropropagación in vitro de germoplasma de cuatro especies de calabaza (C. pepo, C. moschata, $C$. argyrosperma y $C$. ficifolia) resistentes a herbicidas selectivos usados en maíz (atrazina, linurón y simazina), con la idea de utilizarlos en el sistema asociación maíz-calabaza para el control químico de maleza. Usó como explantes las yemas de las puntas tiernas de las guías de plantas establecidas en campo de 50 días de edad con un segmento de tallo de $1 \mathrm{~cm}$ de longitud en el medio de cultivo MS adicionando $1 \mathrm{mg} / \mathrm{l} \mathrm{de}$ BAP. Reportó tasas de multiplicación de 2,2; 3,4; 3,7 y 4,4 para el primero, segundo, tercero y cuarto subcultivo lo que indica una tendencia evidente a incrementar el número de brotes por explante en cada subcultivo. Dicho comportamiento se atribuye a que el autor utilizó como explantes puntas de guías de calabaza provenientes de campo, y al no desinfectarlas adecuadamente se perdió material en los primeros subcultivos, de ahí que la tasa de multiplicación se incrementara conforme se controló el problema de contaminación inicial; mientras que en el presente estudio se utilizaron semillas germinadas in vitro con lo que se garantizó un explante (yema) libre de contaminación durante el inicio de los subcultivos.

\section{Aclimatización en microinvernadero de plántulas provenientes de cultivo in vitro}

Se encontraron diferencias estadísticas significativas y altamente significativas, al 5 y $1 \%$ de probabilidad, respectivamente, para plántulas aclimatizadas
(PLA), número de hojas (NUH) y altura de planta (ALP) en dos variedades de calabaza provenientes de cultivo in vitro que sobrevivieron durante el proceso de aclimatización (Cuadro 4).

Cuadro 4. Cuadrados medios de plántulas aclimatizadas, altura de planta y número de hojas en dos variedades de calabaza provenientes de cultivo in vitro. Chapingo, México. 2004.

\begin{tabular}{lccc}
\hline $\begin{array}{l}\text { Fuentes de } \\
\text { variación }\end{array}$ & PLA & ALP & NUH \\
\hline Variedades & $141,1667 *$ & $23,7752 * *$ & $3,0133 *$ \\
Error & 11,82 & 2,94 & 0,6537 \\
Total & & & \\
CV $(\%)$ & 22,99 & 10,69 & 10,73 \\
$\mathrm{R}^{2}$ & 0,42 & 0,82 & 0,55 \\
\hline
\end{tabular}

C.V.= Coeficiente de variación $(\%) ; \mathrm{R}^{2}=$ Coeficiente de determinación; PLA= Plántulas aclimatizadas; $\mathrm{ALP}=$ Altura de planta; NUH= Número de hojas; *= Significancia de los tratamientos al 0,05 de probabilidad; $* *=$ Significancia de los tratamientos al 0,01 de probabilidad.

Durante el proceso de aclimatización, se registraron 18,02 plántulas por charola en la variedad 'Brujita' lo que representó un $90,10 \%$ de sobrevivencia de plántulas (Cuadro 5). Esto es consistente con lo encontrado por Enríquez et al. (2005), quienes en plantas de crisantemo (Dendranthema grandiflora cv. Polaris White) obtenidas de cultivo in vitro y que crecieron durante cinco semanas en macetas con mezclas de sustratos y con varias dosis

Cuadro 5. Prueba de comparación múltiple de medias por Tukey $(\mathrm{P} \leq 0,05)$ para sobrevivencia de plántulas en dos variedades de calabaza provenientes de cultivo in vitro. Chapingo, México. 2004.

\begin{tabular}{lcc}
\hline Variedad & $\begin{array}{c}\text { Media de sobrevivencia } \\
\text { de plántulas por charola }\end{array}$ & $\begin{array}{c}\text { Sobrevivencia } \\
(\boldsymbol{\%})\end{array}$ \\
\hline 'Brujita' & $18,02 \mathrm{a}$ & 90,10 \\
'Round Zucchini' & $14,75 \mathrm{~b}$ & 73,75 \\
DMS* & 3,23 & \\
\hline
\end{tabular}

* DMS=Diferencia mínima significativa de Tukey al 0,05 de probabilidad. 
de fertilización, el 95\% de ellas se adaptaron bien a las condiciones de invernadero. En 'Round Zucchini' sobrevivieron 14,75 plántulas por charola $(73,75 \%)$ durante el proceso de aclimatización (Cuadro 5). Urbanek et al. (2004) al transferir a suelo plantas de calabaza de cultivo in vitro, que medían entre 4 y $6 \mathrm{~cm}$ de longitud y tenían un diámetro de tallo de $0,3 \mathrm{~cm}$, observaron un 25 $30 \%$ de mortalidad en dos semanas, debido a infecciones por hongos, por lo que solo tuvieron un $65-70 \%$ de plantas con desarrollo normal.

En la presente investigación, las variantes en porcentaje de sobrevivencia de plántulas provenientes de cultivo in vitro para los dos genotipos se asociaron con diferencias en porte y vigor de las plántulas. Las de la variedad 'Brujita' presentaron buen porte, tallos gruesos y buena consistencia; por su parte, las plántulas de 'Round Zucchini' fueron más grandes, con tallos largos pero de menor consistencia; las cuales pudieron haberse maltratado en su manipulación previa al transplante en charolas para su aclimatización.

La prueba de comparación de medias por Tukey $(\mathrm{P} \leq 0,05)$ detectó que la altura de planta al final del proceso de aclimatización (22 días después del transplante en charolas) fue mayor en 'Round Zucchini', la cual promedió $7,27 \mathrm{~cm}$, mientras que 'Brujita' alcanzó $5,10 \mathrm{~cm}$ (Cuadro 6). La diferencia en altura de planta se explica porque 'Round Zucchini' es de semiguía, mientras que 'Brujita' es arbustiva. Otro factor que influyó en la altura de planta es el sombreado que se les dio a las charolas mediante malla sombra, situación que propició que las plantas al encontrarse plenamente aclimatizadas, al eliminar el plástico que cubría a las charolas, empezaran a competir entre sí por luz, provocando etiolación de las mismas.

Cuadro 6. Prueba de comparación múltiple de medias por Tukey $(\mathrm{P} \leq 0,05)$ para altura de planta y número de hojas en dos variedades de calabaza al final del proceso de aclimatización. Chapingo, México. 2004.

\begin{tabular}{lcc}
\hline Variedad & $\begin{array}{c}\text { Altura de planta } \\
(\mathbf{c m})\end{array}$ & $\begin{array}{c}\text { Número de } \\
\text { hojas }\end{array}$ \\
\hline 'Round Zucchini' & $7,27 \mathrm{a}$ & $4,63 \mathrm{a}$ \\
'Brujita' & $5,10 \mathrm{~b}$ & $3,70 \mathrm{~b}$ \\
DMS* & 0,85 & 0,53 \\
\hline
\end{tabular}

* DMS= Diferencia mínima significativa de Tukey al 0,05 de probabilidad.
La variedad 'Round Zucchini' acumuló 4,63 hojas por planta, mientras que 'Brujita' tuvo 3,70 hojas por planta al final del proceso de aclimatización (Cuadro 6). Como información adicional se indica que partiendo originalmente de cinco semillas de las variedades de calabacita 'Round Zucchini' y 'Brujita', se obtuvieron 118 y 126 plantas por variedad, que se transplantaron en tezontle rojo en invernadero (Figura 1G), las cuales produjeron frutos (Figuras 1H y $1 \mathrm{~J}$ ) que se autofecundaron para obtener semillas (Figuras 1I y 1K). Esto en aproximadamente cinco meses, situación que no se hubiese logrado al sembrar cinco semillas por variedad directamente en campo, quedando de manifiesto las bondades que proporciona la técnica de micropropagación in vitro, cuando se dispone de poca semilla básica de calabacita y se pretende realizar incrementos.

\section{CONCLUSIONES}

La tasa de multiplicación promedio de la variedad de calabacita 'Round Zucchini' productora de semilla sin testa fue de 3,2 brotes por explante, subcultivando cada $22 \pm 2$ días, utilizando el medio básico de cultivo MS adicionado con $1,0 \mathrm{mg} / 1$ de 6-Bencilaminopurina (BAP), mientras que la tasa de multiplicación de la variedad 'Brujita' fue de 2,7 brotes por explante.

Se encontró una disminución en la capacidad de regeneración de brotes por explante conforme aumentó el número de subcultivos. En el primero el promedio fue de 3,43 brotes por explante y en el quinto subcultivo se generaron 2,70 brotes por explante.

Durante el proceso de aclimatización se logró una eficiencia del $90,10 \%$ de plántulas que sobrevivieron en la variedad 'Brujita', y de 73,75\% en la variedad 'Round Zucchini' en un lapso de veinte días.

Partiendo originalmente de cinco semillas de las variedades de calabacita 'Round Zucchini' de semilla sin testa y 'Brujita', fue posible obtener 118 y 126 plantas, respectivamente, que produjeron frutos con semillas en un lapso de cinco meses, situación que no se hubiese logrado al sembrar estas mismas semillas directamente en campo por el riesgo de perder material por incidencia de plagas, enfermedades y malezas o por condiciones climatológicas adversas durante el ciclo del cultivo, quedando de manifiesto las bondades que proporciona la técnica de micropropagación in vitro, cuando se dispone de poca semilla básica de calabacita y se pretende realizar incrementos. 


\section{LITERATURA CITADA}

Ammirato, PV; Evans, R; Sharp, R; Bajaj, YPS. 1990. Handbook of plant cell culture, vol. 5: ornamental species. McGraw-Hill. New York, USA. 833 p.

Ananthakrishnan, G; Xia, X; Elman, C; Singer, S; Paris, HS; Gal-On, A; Gaba, V. 2003. Shoot production in squash (Cucurbita pepo L.) by in vitro organogenesis. Plant Cell Rep. 21: 739-746.

Bautista, RF. 2004. Selección y multiplicación in vitro de calabazas (Cucurbita spp.) resistentes a herbicidas usados en maíz. Tesis de Maestría en Ciencias en Horticultura. Universidad Autónoma Chapingo. Chapingo, México. $63 \mathrm{p}$.

Brainerd, KE; Fuchigami, LH. 1981. Aclimatization of aseptically cultured apple plants to low relative humidity. J. Amer. Soc. Hort. Sci. 106: 515-518.

Conger, BV. 1981. Cloning agricultural plants via in vitro techniques. Ed. CRC Press, Inc. Florida. 273 p.

Enríquez Del V, JR; Velásquez, B; Vallejo, AR; Velasco, VA. 2005. Nutrición de plantas de Dendrathema grandiflora obtenidas in vitro durante su aclimatación en invernadero. Rev. Fitotec. Mex. 28(4): 377-384.

Gambley, RL; Dood, WA. 1991. The influence of cotyledon in axilary and adventitious shoot production from cotyledonary nodes of Cucumis sativus (Cucumber). J. Exp. Bot. 42: 1131-1135.

García, E. 1988. Modificaciones al sistema de clasificación climática de Köppen. 4 ed. Instituto de Geografía, Universidad Nacional Autónoma de México, DF. 219 p.

Hiroshi, E; Chung, WI; Lee, YK. 2003. Efficient plant regeneration via organogenesis in winter squash (Cucurbita maxima Duch.). Plant Science 164: 413-418.

Iracheta, L. 1995. Evaluación de la tolerancia in vitro e in vivo al $\mathrm{NaCl}$ en Lycopersicon esculentum Mill. Tesis de Maestría en Ciencias. Programa en Genética. Colegio de Postgraduados. Montecillo, México. 104 p.
Kathiravan, KG; Vengedesan, D; Singer, B; Paris, HS; Gaba, V. 2006. Adventitious regeneration in vitro occurs across a wide spectrum squash (Cucurbita pepo L.). Plant Cell Tissue and Organ Culture 85: 285-295.

Kumar, HGA; Murthy, HN; Paek, KY. 2003. Embryogenesis and plant regeneration from anther cultures of $\mathrm{Cucu}$ mis sativus L. Scientis Hort. 98: 213-222.

Larkin, PJ; Scowcroft, WR. 1981. Somaclonal variation - a novel source of variability from cell cultures for plant improvement. Theor. Appl. Genet. 60: 197-214.

Lee, CW; Thomas, JC. 1985. Tissue culture propagation of buffalo gourd. HortScience 20: 218-219.

Litz, RE; Jarret, RL. 1991. Regeneración de plantas en el cultivo de tejidos: embriogénesis somática y organogénesis. In: Roca, WM; Mroginski, LA. eds. Cultivo de tejidos en la agricultura, fundamentos y aplicación. CIAT. Cali, Colombia. p. 143-172.

López, MC; Sánchez, CI; Muñoz, IS. 1992. Propagación in vitro de jitomate. In: Memorias del XIV Congreso Nacional de Fitogenética. UNACH. Tuxtla Gutiérrez, Chiapas, México. 17 p.

Martínez, J; Warid, WA; Loaiza, JM. 1996. Improvement of naked seed squash, Cucurbita pepo L., in Sonora, Mexico: In: Gómez-Guillamón, ML; Soria, C; Cuartero, J; Torés, JA; Fernández-Muñoz, R. eds. Cucurbits Towards 2000. Proceedings of the 6th Eucarpia Meeting on Cucurbit Genetics and Breeding. Gráficas Axarquía, Málaga. p. 66-71.

Metwally, EI; Moustafa, SA; El-Sawy, BI; Shalaby, TA. 1998. Haploid plantlets derived by anther culture of Cucurbita pepo. Plant Cell Tissue and Organ Culture 52: 171-176.

Mishra, AK; Bhatnagar, SP. 1995. Direct shoot regeneration from the leaf explant of Cucumber (Cucumis sativus L.). Phytomorphology 45: 47-55.

Murashige, T; Skoog, F. 1962. A revised medium for rapid growth and bioassays with tobacco tissue cultures. Physiol. Plant. 15: 473-497. 
Murashige, T. 1974. Plant propagation through tissue culture. Annu. Rev. Plant Physiol. 25: 135-136.

Paris, S. 2000. Segregation distortion in Cucurbita pepo L. Proc. Cucurbitaceae 2000. eds. N. Katzir \& H. S. Paris. Acta Horticulturae. 510. ISHS. 2000.

Pierik, LM. 1990. Cultivo in vitro de las plantas superiores. Ed. Mundi-Prensa. Madrid, España. 326 p.

Pink, AC; Walkey, GA. 1984. Rapid propagation of Cucurbita pepo L. by culture of meristems tips. Sci. Hortic. (Amst.) 24: 107-114.

Quintanilla, KM. 2007. Establecimiento in vitro de loroco (Fernaldia pandurata Woodson). Agronomía Mesoamericana 18: 75-84.

Read, PE; Fellman, CD. 1985. Accelerating acclimatization of in vitro propagated woody ornamentals. Acta Horticulturae 166: 15-20.

Sánchez, MA; Mejía, A; Villanueva, C; Sahagún, J; Sánchez, C; Jiménez, MC. 2006. Determinación del tamaño adecuado de parcela experimental en calabaza pipiana (Cucurbita argyrosperma Huber var. Stenosperma). Rev. Fitotec. Mex. 29(4): 339-348.

Santalla MJ; Power JB; Davey, MR. 1998. Efficient in vitro shoot regeneration responses of Phaseolus vulgaris and P. coccineus. Euphytica 102: 195-202.

Sarowar, S; Oh, NY; Hyung, NI; Min, BW; Harn, CH; Yang, SK; $\mathrm{Ok}, \mathrm{SH}$; Shin, JS. 2003. In vitro micropropagation of a Cucurbita interspecific hybrid cultivar - a root stock plant. Plant Cell, Tissue and Organ Culture 75: 179-182.

SAS Institute INC. 1989. SAS/STAT User's Guide. Version 6.01. SAS Institute Inc., Cary, NC, USA. 479 p.
Segura, J. 1993. Morfogénesis in vitro. In: Fisiología y bioquímica vegetal. Azcon, BJ; Talón, M. ed. Editorial Interamericana. Nueva York, USA. 581 p.

Shakti, PP; Iftekhar, A; Anisuzzaman, M; Kanak, KS; Shamima, AS; Mohammad, FA. 2007. Indirect organogenesis in summer squash (Cucurbita pepo L.). Turk. J. Agric. For. 31: 63-70.

Sheridan, WF. 1988. Maize developmental genetics: genes of morphogenesis. Ann. Rev. Genet. 22: 353-385.

Steiner, AA. 1984. The universal nutrient solution. Proceeding International Congress on Soilless Culture 6: 633-650.

Stripp, LCL; Mendez, BMJ; Piedade, SMDS; Rodríguez, A PM. 2001. In vitro morphogenesis of Cucumis melo var. Inodorus. Plant Cell Tissue and Organ Culture 65: 81-89.

Urbanek, A; Zechmann, B; Müller, M. 2004. Plant regeneration via somatic embryogenesis in Styrian pumpkin: cytological and biochemical investigations. Plant Cell, Tissue and Organ Culture 79: 329-340.

Vasil, IK; Thorpe, TA. 1994. Plant cell and tissue culture. Kluwer Academic Publishers. Netherlands. 593 p.

Villanueva, C; Merrick, LC; Martínez, A; Martínez, JA; Meneses, I; Nájera, E; Rodríguez, ML; Sánchez, MA; Vildozola, JL. 1998. Landraces in México. In: J D Mc Creight. ed. Cucurbitaceae '98. ASHR Press. Alex., Va. p. $38-42$.

Winkler, J. 2000. Breeding of hull-less seeded pumpkins (Cucurbita pepo) for the use of the oil. Proc. Cucurbitaceae 2000. Katzir, N; Paris, HS. eds. Acta Horticulturae. 510. ISHS 2000. 